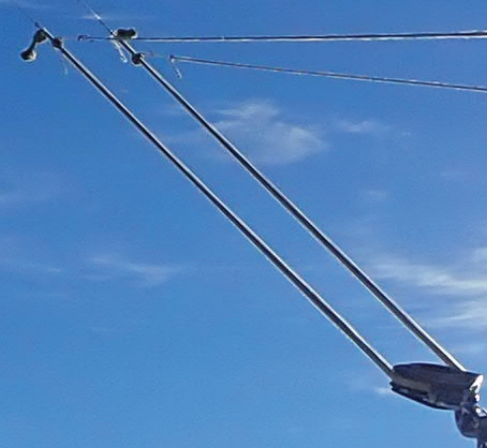

of Remote Polar Areas Using

an AWS Onboard a Unique

Zero-Emissions Polar Vehicle

Sergi Gonzalez, Manuel Bañon, José V. Albero,

Ramón larramendi, Hermenegilldo Moreno, Francisco Vasallo,

PABLO SANZ, ANTONIO QUESADA, AND ANA JUSTEL

I

Weather Observations

Lis 
A the beginning of polar exploration, transects were carried out to record the environmental and weather conditions of the most remote places in Antarctica, largely due to the impossibility of setting up stations for long periods. A good example was the first meteorological data from the most inaccessible areas near the South Pole, which were recorded in the Shackleton, Amundsen, Scott, and Fuchs expeditions to the interior of Antarctica at the beginning of the twentieth century (Walsh et al. 2018). However, after the International Geophysical Year in 1957/58, several research stations were built in Antarctica and most of them included weather stations in their premises, acquiring high-quality meteorological information. At this time, weather data transects on the surface of Antarctica began to lose some relevance.

Currently, other types of transects are being established that are also important in meteorology. Weather data recorded by sensors on board civil aircraft are transmitted in the WMO Global Telecommunications System using the Aircraft Meteorological Data Relay (AMDAR) Observing System. Research aircraft are instrumented to measure atmospheric variables from the troposphere in scientific campaigns, but only a few have measured the atmosphere over Antarctica (e.g., Grosvenor et al. 2012). Vessels collect data over the ocean where there are few observations available. However, terrestrial surface transects are rare and would be very valuable for the polar regions, where stations are far apart. Despite all the efforts made to install weather stations over the entire continent, they are unevenly

affiliations: Gonzalez, Bañon, Albero, and VasalloAntarctic Group, Agencia Estatal de Meteorología, Madrid, Spain; LARRAMENDI AND MoReno-Inuit WindSled Polar Society, Madrid, Spain; SANZ-Scientific Computing Centre, Universidad Autónoma de Madrid, Madrid, Spain; QUESADA-Department of Biology, Universidad Autónoma de Madrid, Madrid, Spain; Justel-Department of Mathematics, Universidad Autónoma de Madrid, and UC3M-Santander Big Data Institute (IBiDat), Universidad Carlos III de Madrid, Madrid, Spain

CORRESPONDING AUTHOR: S. Gonzalez, sgonzalezh@aemet.es

The abstract for this article can be found in this issue, following the table of contents.

DOI:10.1175/BAMS-D-19-0110.1

(C)2019 American Meteorological Society

For information regarding reuse of this content and general copyright information, consult the AMS Copyright Policy. distributed. The majority are located next to the small number of research stations or are concentrated in the area of influence of a research team. For instance, the Antarctic Meteorological Research Center at the University of Wisconsin-Madison maintains a network of automatic weather stations (AWS) operating in a large area covering the Ross Ice Shelf and the West Antarctic Ice Sheet (Lazzara et al. 2012). In the East Antarctic Plateau, the density of surface weather stations is even lower. Although the lack of ground observations on the Antarctic Plateau is being compensated for by the simulations provided by mathematical models, shortand medium-range weather forecasts present reduced accuracy (Jung et al. 2016), which has consequences for matters as important as forecasting, climate change modeling, atmospheric transport, etc.

The Year of Polar Prediction (YOPP) highlights the need for increasing observations and data collection on areas with few stations, like the Antarctic Plateau. Given the unlikely deployment of new AWS in this vast territory by inexpensive methods, the surface data obtained in transects can be an effective support for the objective of increasing observations during the YOPP Southern Hemisphere Special Observing Period (YOPP-SH SOP). Unfortunately, the most common ways of moving in the interior of Antarctica, with convoys of highly polluting vehicles, are also costly and have an adverse ecological footprint (Rosen 2017).

To move across the ice without carbon emissions, a polar vehicle with a maximum load of 2 tons was designed to make environmentally sustainable and economically efficient scientific explorations in the most inaccessible areas of the ice sheet. This vehicle is known as WindSled (www.greenland.net/windsled) because its engine is a set of kites of different sizes (from 30 to $150 \mathrm{~m}^{2}$ ) that takes advantage of the wind force to sledge across the ice sheet, making it a zeroemissions moving scientific platform (Fig. 1).

In the 2018/19 austral summer, coinciding with the YOPP-SH SOP, the WindSled team carried out its first scientific expedition "Antarctica Unexplored Dome Fuji 2018/19." The scientific campaign followed a transect of $2,538 \mathrm{~km}$ on a route that approached Dome Fuji (altitude: 3,810 m) from the plateau near the Novolazárevskaya station located on the coast. Throughout the expedition, a mobile AWS called M-AWS, installed on the sled by the MICROAIRPOLAR project of the Universidad Autónoma de Madrid (Spain) and the Spanish Meteorological Service (AEMET), recorded several meteorological variables at high resolution 


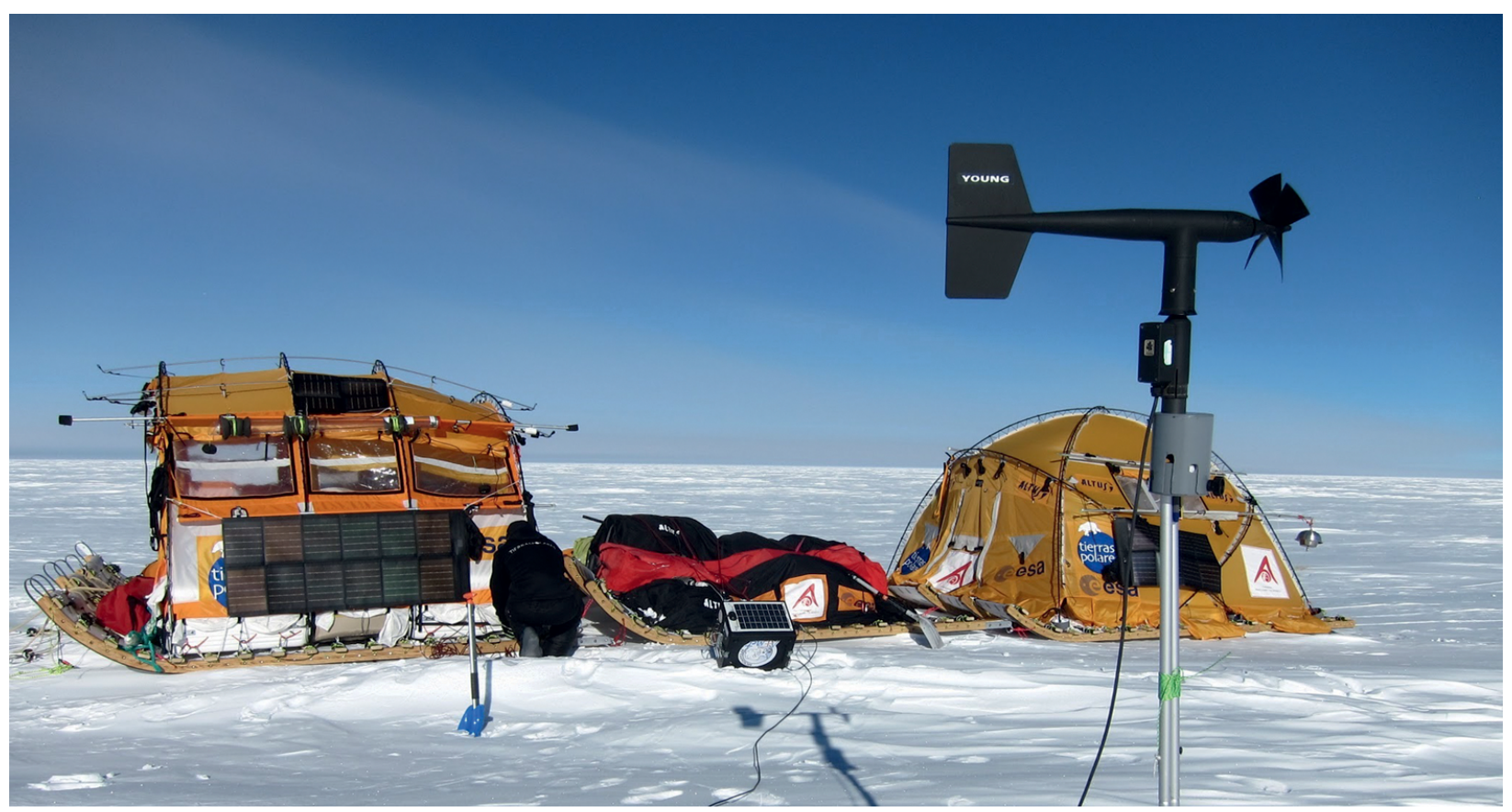

FIG. I. WindSled and meteorological instruments during the expedition "Antarctica Unexplored Dome Fuji 2018/19."

on a spatial scale. The M-AWS was specially designed to provide high-quality surface records following the WMO standards over one of the most inaccessible areas of East Antarctica's inland.

The M-AWS design had to face four main challenges: 1) being able to operate at temperatures below $-40^{\circ} \mathrm{C}$, 2) being able to withstand shocks caused by the movement of the WindSled when passing over the sastrugi, 3) minimizing energy consumption, and

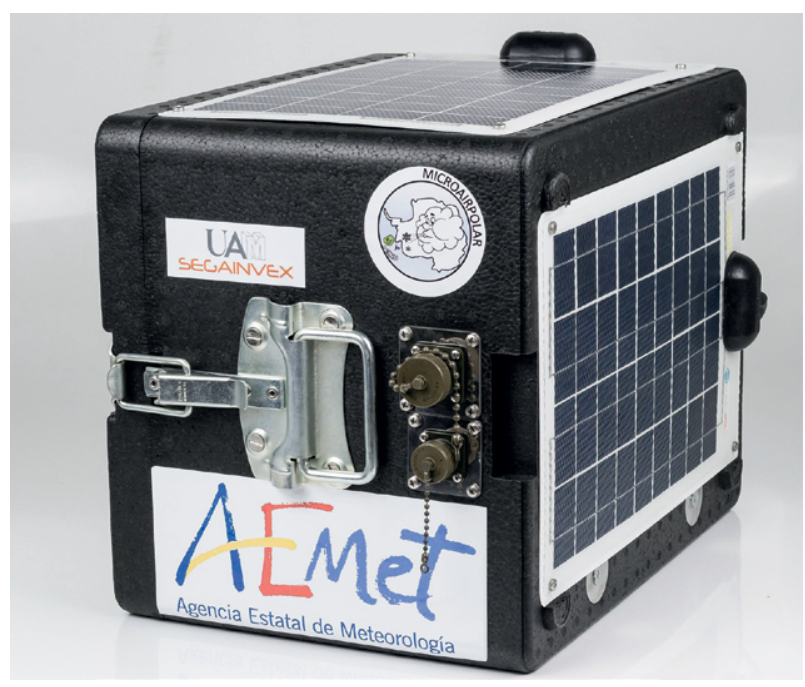

FIG. 2. The main body of the M-AWS where datalogger, batteries, GPS, and heater are located.
4) geolocating the data using GPS. To achieve these purposes, the datalogger and the GPS were placed in an isothermal padded container of expanded polyethylene (Fig. 2) and were powered by a custom-made lithium battery, with enough capacity to endure a 2-month campaign without recharging, considering the discharge rates at low temperatures, and the consumption of the meteorological sensors, the datalogger, and the associated GPS. To ensure the operation of the datalogger and the GPS, and to improve the efficiency of the battery, an electrical resistance powered by two 10 -W solar cells that heated the container was installed. Meteorological instruments were connected with connectors and cables suitable for low temperatures and shock resistant. M-AWS was instrumented with a wind sensor and a temperature and relative humidity probe (Table 1), but the system was prepared for accepting further instruments. Figure 3 shows the track of the transect determined from the GPS signals and the temperature every $30 \mathrm{~min}$.

The M-AWS functioned properly, and data were collected and stored during most of the transect. Regarding the design, the cables delivering energy from the solar panels to the electrical resistances inside the M-AWS container could not be substituted by high-performance cables, since they were heatsealed, and in fact broke on the eighth day due to the cold and movement. The internal resistances were 


\begin{tabular}{|c|c|c|c|}
\hline \multicolumn{4}{|c|}{ TABLE I. M-AWS meteorological instruments. $\mathrm{RH}$ is relative humidity, $T$ is temperature, and I knot $(\mathrm{kt})=0.5 \mathrm{I} \mathrm{\textrm {m } \mathrm { s } ^ { - 1 }}$} \\
\hline Instrument & Sensor & Range & Accuracy \\
\hline Datalogger & Campbell CRI000 & - & - \\
\hline Temperature probe & Vaisala HMPI55 & $-80^{\circ}$ to $+60^{\circ} \mathrm{C}$ & $\pm(0.176-0.0028 T)^{\circ} \mathrm{C}$ \\
\hline Relative humidity probe & Vaisala HMPI55 & $0 \%$ to $100 \%$ & $\pm(1.2+0.012 \times R H) \%$ \\
\hline Wind sensor & Young 05108-45-L & $\begin{array}{c}0 \text { to } 100 \mathrm{~m} \mathrm{~s}^{-1} \\
0^{\circ} \text { to } 360^{\circ} \text { mechanical }\end{array}$ & $\begin{array}{c} \pm 0.3 \mathrm{~m} \mathrm{~s}^{-1} \text { or } 1 \% \text { of speed } \\
\pm 3^{\circ}\end{array}$ \\
\hline \multirow{2}{*}{ GPS } & \multirow{2}{*}{ Garmin GPS $16 \mathrm{x}-\mathrm{HVX}$} & $\begin{array}{l}\text { Operating temperature: } \\
-30^{\circ} \text { to }+80^{\circ} \mathrm{C}\end{array}$ & $\begin{array}{l}\text { Position }<15 \mathrm{~m} \\
95 \% \text { typical }\end{array}$ \\
\hline & & $\begin{array}{l}\text { Storage temperature: } \\
\qquad-40^{\circ} \text { to }+80^{\circ} \mathrm{C}\end{array}$ & $\begin{array}{l}0.1 \mathrm{kt}, \text { root-mean-square } \\
\text { steady state }\end{array}$ \\
\hline
\end{tabular}

not operating, but the inside of the box remained around $10^{\circ} \mathrm{C}$ above the outside temperature and the data collection was not compromised. Wind data were not collected since the wind sensor associated with the station failed. The aerovane was too heavy to be supported by the custom-produced tripod during the movement above the sastrugi. This shows that, for future expeditions, in addition to the appropriate choice of instruments, it is necessary to devote special attention to their secure placement in the sled.

The data collected were used to improve the weather forecasts provided by AEMET staff during the expedition to remotely assist the WindSled team in logistics and movements. The acquired data were also used to meet the demand for meteorological observations of the expedition's scientific activities. Last, but not least, these data become very valuable information to review the behavior of meteorological models in this data-sparse area of the Antarctic
AWS network over the East Antarctic Plateau. Despite the large amount of data that satellites offer for the assimilation of the meteorological models, in situ ground observations, especially on the poles, are truly needed (Jung et al. 2016). Even if the observations are not assimilated into the analyses, they can still be used to evaluate the meteorological models as they provide independent data for the validation process.

The weather observations from this expedition will be added to the YOPP database at PANGEA. Nevertheless, for future expeditions, a potential objective is to integrate the data into the WMO's Global Telecommunication System for assimilation into operational weather systems. The growing interest in the polar regions, which has recently emerged due to the challenges imposed by climate change, requires an increase in the quantity and quality of data whenever possible through inexpensive and environmentally sustainable methods.

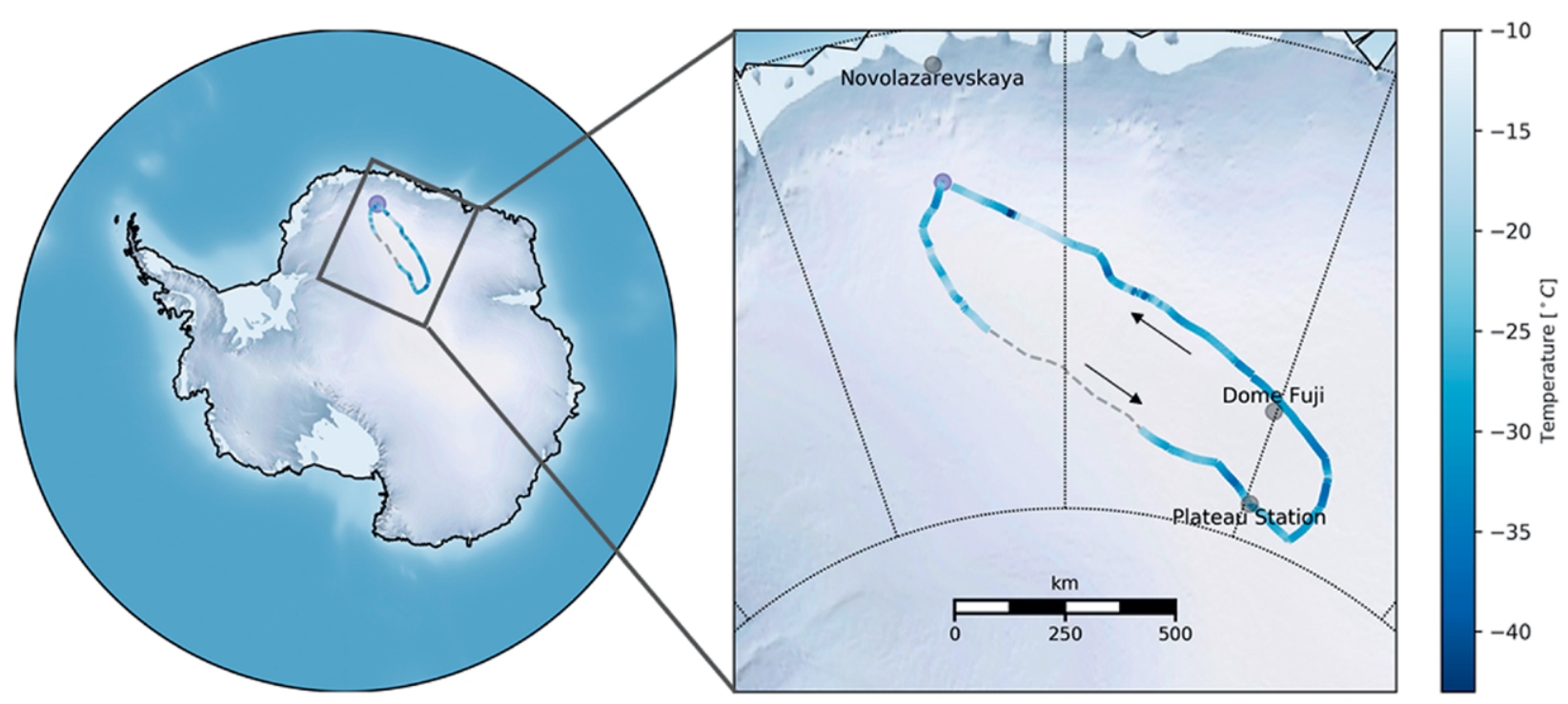

FIG. 3. GPS track and temperatures during the scientific expedition “Antarctica Unexplored Dome Fuji 20I8/19.” 
ACKNOWLEDGMENTS. This is a contribution to the Year of Polar Prediction (YOPP), a flagship activity of the Polar Prediction Project (PPP), initiated by the World Weather Research Programme (WWRP) of the World Meteorological Organization (WMO). MICROAIRPOLAR is a project founded by AEI (Spain) and ERDF (EU), CTM2016-79741-R grant. AEMET Antarctic program is supported by the MSIU (Spain). Sergi Gonzalez's research activities are partly supported by ANTALP Research Group funded by Generalitat de Catalunya (2017 SGR 1102). Our thanks to J.A. Higuera and J. González from SEGAINVEX-UAM, R. Vicente from AEMET, and expedition members I. Oficialdegui and M. Olivera for their very valuable contribution to the project. We also acknowledge the two anonymous reviewers whose input has helped improve this article.

\section{FOR FURTHER READING}

Fogt, R. L., M. E. Jones, S. Solomon, J. M. Jones, and C. A. Goergens, 2017: An exceptional summer during the South Pole Race of 1911/12. Bull. Amer. Meteor. Soc., 98, 2189-2200, https://doi.org/10.1175/BAMS -D-17-0013.1.
Grosvenor, D. P., T. W. Choularton, T. Lachlan-Cope, M. W. Gallagher, J. Crosier, K. N. Bower, R. S. Ladkin, and J. R. Dorsey Jr., 2012: In-situ aircraft observations of ice concentrations within clouds over the Antarctic Peninsula and Larsen Ice Shelf . Atmos. Chem. Phys., 12, 11 275-11 294, https://doi .org/10.5194/acp-12-11275-2012.

Jung, T., and Coauthors, 2016: Advancing polar prediction capabilities on daily to seasonal time scales. Bull. Amer. Meteor. Soc., 97, 1631-1647, https://doi .org/10.1175/BAMS-D-14-00246.1.

Lazzara, M. A., G. A. Weidner, L. M. Keller, J. E. Thom, and J. J. Cassano, 2012: Antarctic Automatic Weather Station Program: 30 years of polar observation. Bull. Amer. Meteor. Soc., 93, 1519-1537, https://doi .org/10.1175/BAMS-D-11-00015.1.

Rosen, J., 2017: Sustainability: A greener culture. Nature, 546, 565-567, https://doi.org/10.1038/nj7659-565a.

Walsh, J. E., D. H. Bromwich, J. E. Overland, M. C. Serreze, and K. R. Wood, 2019: 100 Years of progress in polar meteorology. A Century of Progress in Atmospheric and Related Sciences: Celebrating the American Meteorological Society Centennial, Meteor. Monogr., No. 59, Amer. Meteor. Soc., https:// doi.org/10.1175/AMSMONOGRAPHS-D-18-0003.1.

\section{NEW FROM AMS BOOKS!}

\section{Climate in the Age of Empire: \\ Weather Observers in Colonial Canada Victoria C. Slonosky}

Weather observers have been paying close attention to the climate for centuries, at points even hoping human activity would bring change. This book shows how and why the colonialera scientific community amassed a remarkable body of detailed knowledge about Canada's climate and its fluctuations. Covering work by early French and British observers, the book presents excerpts from weather diaries and other records that, more than the climate itself, reveal colonial attitudes toward it.

Victoria C. Slonosky studied climatology at McGill University and the Climatic Research Unit in the UK

GLIMATE IN THE
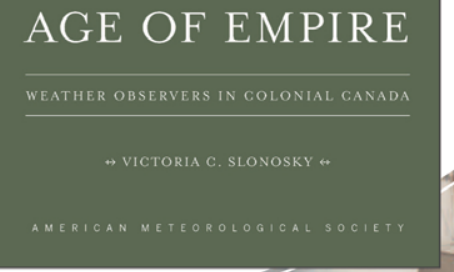


\section{JOIN US FOR THE CULMINATION OF OUR CENTENNIAL CELEBRATION}

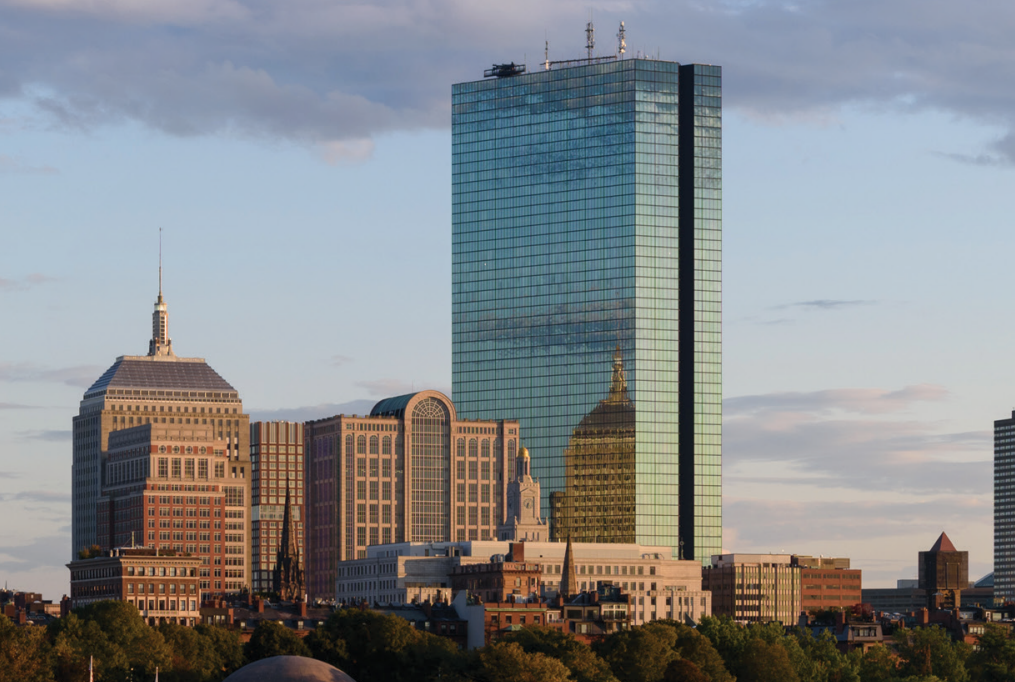

